\title{
Effects of supplemental lighting during the period of rapid fruit development on the growth, yield, and energy use efficiency in strawberry plant production**
}

\author{
Ayami Yoneda ${ }^{1}$, Daisuke Yasutake ${ }^{2}$, Kota Hidaka ${ }^{3}$, Nur I. Muztahidin $^{4,5}$, Yuta Miyoshi ${ }^{6}$, Masahar Kitano $^{2}$, \\ and Takashi Okayasu ${ }^{2}$ \\ ${ }^{1}$ Graduate School of Bioresource and Bioenvironmental Sciences, Kyushu University, 744 Motooka, Nishi-ku, \\ Fukuoka, 819-0395, Japan \\ ${ }^{2}$ Faculty of Agriculture, Kyushu University, 744 Motooka, Nishi-ku, Fukuoka 819-0395, Japan \\ ${ }^{3}$ Kyushu Okinawa Agricultural Research Centre, National Agriculture and Food Research Organization, 1823-1 Miimachi, \\ Kurume, Fukuoka 839-0851, Japan \\ ${ }^{4}$ Faculty of Agriculture, University of Sultan Ageng Tirtayasa, Jl. Raya Jakarta km.04, Serang, 42124, Indonesia \\ ${ }^{5}$ Indonesia Centre of Excellence for Food Security, University of Sultan Ageng Tirtayasa, Jl. Raya Jakarta km.04, \\ Serang, 42124, Indonesia \\ ${ }^{6}$ National Institutes for Quantum and Radiological Science and Technology, 1233 Watanukimachi, Takasaki, Gunma 370-1292, Japan
}

Received September 27, 2019; accepted January 29, 2020

\begin{abstract}
Supplemental lighting techniques in greenhouses can increase plant growth and yield but require substantial amounts of energy. We proposed the use of energy-saving supplemental lighting, which was applied during rapid fruit development when the transport of photosynthetic products into the fruit was active. We measured the physiological responses (photosynthesis, growth, yield) of the strawberry plants with single fruit truss, wherein the following 3 treatments were made: plants were cultivated with no supplemental lighting (control), supplemental lighting throughout the experimental period (normal-light), and supplemental lighting during rapid fruit development (short-light). The period of rapid fruit development corresponded to $33 \%$ of the experimental period, and the cumulative light intensity for the short-light treatment was half of that for the normal-light treatment, and twice that of the control treatment. Consequently, the leaf area and dry weight of the plant body were significantly increased following normal-light and short-light treatments compared with the control treatment. The yield for the short-light treatment was also increased and nearly equal to that of the normal-light treatment but no significance to the control treatment. However, the energy
\end{abstract}

\footnotetext{
*Corresponding author e-mail: yasutake@bpes.kyushu-u.ac.jp **This work was financially supported by the Project of the National Agriculture and Food Research Organization Biooriented Technology Research Advancement Institution (Special Scheme Project on Regional Developing Strategy; No. 16822352, 2016-2019) and the Grants-in-Aid for Scientific Research (Japan Society for the Promotion of Science; No.17H03895 and No. 18K05905, 2017-2020).
}

use efficiency of the short-light was improved 1.5-fold compared to the normal-light treatment. Thus, shortening the period of supplemental lighting in accordance with the characteristics of fruit development is potentially effective.

Keywords: energy-saving, environmental control, greenhouse, LED, translocation

\section{INTRODUCTION}

In protected horticulture, various environmental control techniques have recently been developed and widely used to promote the photosynthesis and growth of crops. In particular, supplemental lighting should be an effective way of achieving this under conditions which provide insufficient light. For example, Hidaka et al. (2016) achieved a twofold increase in strawberry yield through the combined application of LED lighting and $\mathrm{CO}_{2}$ enrichment. As similar effects on crop growth and yield have been demonstrated previously by a variety of other studies (Martine et al., 1990; Andre et al., 1996; Demers et al., 1998; Hidaka et al., 2013), these techniques should be considered as essential for crop production in protected horticulture.

(C) 2020 Institute of Agrophysics, Polish Academy of Sciences 
Unfortunately, the application of these environmental controls require a large amount of energy resources (Bakker et al., 2008) because the environmental control of greenhouses is usually carried out throughout the cultivation period (Heuvelink 2005, Hidaka et al., 2013, 2014, 2015), and the extensive use of energy resources increases the cost burden of crop production (Heuvelink 2005). Also, energy resources are mainly derived from fossil fuels, so the use of environmental controls will produce more $\mathrm{CO}_{2}$ emissions and contribute to the environmental load. In fact, greenhouse gas emissions from global agriculture increased by an average of $1.6 \% \mathrm{y}^{-1}$ from 1961 to 2010 (Tubiello et al., 2013). Therefore, while retaining the boosting effects on crop growth and yield, it is necessary to develop techniques that can save energy by shortening the period of environmental control.

It is well known that not only photosynthesis but also the translocation of photosynthesis products are important factors in the determination of yields, especially of fruit vegetables (Heuvelink, 2005). After pollination, fruit usually develop according to a logistic curve, in which the gradient of the curve is larger around the middle-period between pollination and harvesting (Kassai et al., 2002). During the period with the larger curve gradient, fruit develop actively, which indicates that mass transports into fruit via phloem and xylem tubes are also active. In fact, Araki et al. (2000) reported that activated phloem and xylem sap fluxes significantly increased fruit growth. In other words, fruit should require large amounts of photosynthesis products by translocation during the active fruit development period ( $\mathrm{Li}$ et al., 2001). It has also been reported that the application of supplemental lighting during the period of rapid fruit development had more of an effect on the growth and yield of first-truss tomato plants than during any other periods $(\mathrm{Lu}$ et al., 2011).

Accordingly, the aim of this study was to test the hypothesis that the application of supplemental lighting during the period of active fruit development could increase both fruit yield and energy savings, when compared to the application of supplemental lighting over the entire cultivation period. In this study, we therefore carried out an experiment to test the hypothesis by applying supplemental lighting from LED sources to strawberry plants, the effects of which were already demonstrated by previous studies (Hidaka $e t$ al., 2013). Moreover, we investigated a single fruit truss (third fruit truss) of strawberries to observe the effect more precisely.

\section{MATERIALS AND METHODS}

In order to investigate the effects of short-term supplemental lighting, strawberry plants (Fragaria $\times$ ananassa Duch. 'Fukuoka S6') were grown in a large-scale greenhouse $(37 \mathrm{~m}$ long $\times 9 \mathrm{~m}$ wide $\times 4.5 \mathrm{~m}$ high) that was located at the National Agriculture and Food Research
Organization (Kyushu Okinawa Agricultural Research Centre, Japan; $33^{\circ} 18.4^{\prime} \mathrm{N}, 130^{\circ} 32.8^{\prime} \mathrm{E}$ ). Nursery plants were selected from mother stocks and planted in plastic pots that were filled with a 3:5:2 (v:v:v) mixture of peat moss, coconut shell, and charcoal on June 13, 2016. A nutrient solution (OK-F-1; OAT Agrio Co., Ltd., Tokyo, Japan), with an electrical conductivity of $0.6 \mathrm{dS} \mathrm{m}^{-1}$, was supplied at a rate of $300 \mathrm{~mL} \mathrm{~d}^{-1} /$ plant at 9:00, 11:00, 13:00, 15:00, and 17:00 each day except for the summer season when it was withheld to induce anthesis. On September 26, 2016 , the nursery plants were transplanted into substratefilled cultivation beds $(1.21 \mathrm{~m}$ long $\times 0.28 \mathrm{~m}$ wide $\times 1.18 \mathrm{~m}$ high), with $0.2 \mathrm{~m}$ between plants and $0.15 \mathrm{~m}$ between rows, the nutrient solution was supplied at a rate of $3 \mathrm{~L}_{\text {plant }}{ }^{-1}$ every day.

These plants were then used to investigate the effects of short-term supplemental lighting, the experimental period lasted from anthesis to the harvest of the 3rd truss (March 24 to May 8, 2017). Ten strawberry plants were allocated to each treatment, as described below, and the number of leaves on each plant was maintained at about 7 during the experimental period to investigate the effects of supplemental lighting on leaf area.

The strawberry plants were assigned to one of three treatments. The normal-light treatment included supplemental lighting with LED light (LLM0312A; Stanley Electric Co., Ltd., Japan) during the entire experimental period, from anthesis to harvest, whereas the short-light treatment included supplemental lighting with LED light from April 13 to April 28, which corresponded to the period of active fruit development, and the control treatment did not involve any supplemental lighting. In the normaland short-light treatments, four LED light sources were installed at a height of $50 \mathrm{~cm}$ above the plant base and used with a $12 \mathrm{~h}$ photoperiod (6 a.m. -6 p.m.), according to Hidaka et al. (2014). The spectral distributions of the LED light were reported by Hidaka et al. (2013), in which the peaks in light intensity appeared at wavelengths of 450 and $550 \mathrm{~nm}$, and the LED light appeared to be white.

In order to investigate the cultivation environments of the strawberry plants, the photosynthetic photon flux density (PPFD) of each treatment was measured using photon quantum sensors (PAR-02; Prede Co., Ltd., Tokyo, Japan) that were placed at the top of the strawberry canopy, which was $20 \mathrm{~cm}$ above the plant bases. The PPFD data were automatically recorded every $10 \mathrm{~min}$ by a data logger (MIJ-01; Environmental Measurement Japan Co., Ltd., Japan). In addition, the air temperature, relative humidity, and $\mathrm{CO}_{2}$ concentration were measured at $10 \mathrm{~min}$ intervals using a temperature and humidity sensor (HT-20; Azbil Co., Ltd., Japan) and a $\mathrm{CO}_{2}$ sensor (GMM222; VAISALA Co., Ltd., Japan).

The photosynthetic rates of five fully expanded leaflets from each treatment were measured using a leaf chamber system (LI-6400XT; Li-Cor, Inc, USA) from 11-12 a.m. on 
April 18, 2017. The chamber was equipped with a natural window, and the air temperature, relative humidity, and $\mathrm{CO}_{2}$ concentration inside the chamber were maintained at $25^{\circ} \mathrm{C}, 50 \%$, and $400 \mu \mathrm{mol} \mathrm{mol}{ }^{-1}$, respectively.

In order to evaluate the effects of supplemental lighting on plant growth, the total leaf areas of six plants from each treatment were estimated on the first day (March 24, 2017) and last day (May 8, 2017) of the experimental period. Only fully expanded leaflets were measured, and the total leaf area was estimated using an equation previously described by Hidaka et al. (2013):

$$
L A=1.743 L_{1} W_{1}+5.992,
$$

where: $L A$ represents leaf area $\left(\mathrm{cm}^{2}\right), L_{1}$ represents leaf length $(\mathrm{cm})$, and $W_{1}$ represents leaf width $(\mathrm{cm})$.

On the last day of the experiment (May 8, 2017), six plants from each treatment were harvested and separated into their respective organs (leaves, peduncles, and crowns). Each part was dried for $72 \mathrm{~h}$ at $80^{\circ} \mathrm{C}$ in a circulation drier, cooled to room temperature, and weighed.

In order to evaluate the effects of supplemental lighting on fruit development, three fruit were selected from each treatment, and their volume was estimated from fruit length and width, as follows (Hidaka et al., 2013):

$$
V_{F}=0.0004 L_{f} W_{f}^{2}+0.42,
$$

where: $V_{F}$ represents fruit volume $\left(\mathrm{cm}^{3}\right), L_{f}$ represents fruit length $(\mathrm{mm})$, and $W_{f}$ represents fruit width $(\mathrm{mm})$. Furthermore, the fruit growth rate was calculated by dividing the volume of the harvested fruit by the number of days from anthesis to harvest. After the three fruit were harvested, both fresh weight (FW) and dry weight (DW) were measured, and the dry ratio $(\mathrm{DW} / \mathrm{FW})$ of the fruit was calculated.

In order to evaluate the effect of supplemental lighting on the fruit harvest, all fruit were harvested from 10 plants in each treatment and weighed. Fruit with weights of $>6 \mathrm{~g}$ were considered to have a marketable yield.

In order to evaluate the effect of supplemental lighting on the energy use efficiency of strawberry production, the cumulative electric power use of the supplemental lighting was measured using a watt monitor (TAP-TST8; Sanwa Supply Inc., Japan), and energy use per plant $(E U, \mathrm{kWh}$ plant $^{-1}$ ) was calculated by dividing the cumulative electric power use by the number of plants in each treatment. Furthermore, energy use efficiency $\left(E U E, \mathrm{~g} \mathrm{kWh}^{-1}\right)$ was calculated as follows:

$$
E U E=\frac{\Delta M Y}{E U},
$$

where: $\triangle M Y$ represents the increase in the marketable yield of fruit per plant ( $\mathrm{g}$ plant $\left.{ }^{-1}\right)$ under supplemental lighting.

The PPFD and photosynthetic rate during leaf gas exchange measurement, plant growth and fruit yield (leaf area, plant dry weight, fruit volume, fruit fresh weight, fruit dry weight, and fruit dry ratio) were subject to an analysis of variance (ANOVA). Significant differences between the treatments were further examined using a $t$-test or TukeyKramer test at $\mathrm{p}<0.05$ in statistical software $\mathrm{R}$ (ver. i386 3.5.1.)

\section{RESULTS AND DISCUSSION}

The environmental conditions of the greenhouse during the day and night are summarized in Table 1 . The daily mean temperature was consistent with the range considered favourable to strawberry cultivation (i.e., $15-25^{\circ} \mathrm{C}$; Wang et al., 2000). Meanwhile, relative humidity ranged from 70 to $100 \%$ and tended to decrease with time, whereas daily mean $\mathrm{CO}_{2}$ concentration was nearly constant at $500 \mu \mathrm{mol}$ $\mathrm{mol}^{-1}$

Table 1. Environmental conditions of the greenhouse during the experimental period

\begin{tabular}{lccc}
\hline Time & $\begin{array}{c}\text { Air } \\
\text { temperature } \\
\left({ }^{\circ} \mathrm{C}\right)\end{array}$ & $\begin{array}{c}\text { Relative } \\
\text { humidity } \\
(\%)\end{array}$ & $\begin{array}{c}\mathrm{CO}_{2} \\
\text { concentration } \\
\left(\mu \mathrm{mol} \mathrm{mol}{ }^{-1}\right)\end{array}$ \\
\hline $\begin{array}{l}\text { Day } \\
\text { (6 a.m. - 6 p.m.) }\end{array}$ & $23.1 \pm 4.90$ & $76.0 \pm 21.0$ & $490 \pm 50.3$ \\
$\begin{array}{l}\text { Night } \\
\text { (6 p.m. - 6 a.m.) }\end{array}$ & $21.8 \pm 5.6$ & $79.1 \pm 20.9$ & $499 \pm 53.0$ \\
\hline
\end{tabular}

Mean values were shown with \pm standard deviation.

The effects of lighting treatment on PPFD are presented in Fig. 1. The daily integrated PPFD of the control and the normal-light treatments were relatively stable at 10 and $35 \mathrm{~mol} \mathrm{~m}^{-2} \mathrm{~d}^{-1}$, respectively, and the daily integrated PPFD of the short-light treatment was consistent with the control treatment, except during the period of active fruit development (from April 13 to April 28, 2017), when it was consistent with the normal-light treatment. In addition, the final cumulative PPFD of the short-light treatment was approximately twice that of the control treatment and approximately half that of the normal-light treatment.

The effects of lighting treatment on PPFD and the photosynthetic rate between 11:00-12:00 on April 18 are presented in Fig. 2. During the measurement period, the weather was slightly cloudy, and the PPFD of the control treatment was about $100 \mu \mathrm{mol} \mathrm{m} \mathrm{m}^{-2} \mathrm{~s}^{-1}$. However, with the application of supplemental lighting (the normal-light and the short-light treatments), PPFD was increased to $600 \mu \mathrm{mol} \mathrm{m} \mathrm{m}^{-2} \mathrm{~s}^{-1}$, as a result, the photosynthetic rate was increased significantly by 3.0 times, when compared to the control treatment. According to Hidaka et al. (2013), the light saturation point of strawberry ('Fukuoka S6') is $400 \mu \mathrm{mol} \mathrm{m} \mathrm{m}^{-2} \mathrm{~s}^{-1}$ under a $\mathrm{CO}_{2}$ concentration of $400 \mu \mathrm{mol}$ $\mathrm{mol}^{-1}$. During the day, the $\mathrm{CO}_{2}$ concentration over the course of the experiment was approximately $490 \mu \mathrm{mol}$ $\mathrm{mol}^{-1}$ on average. This means that the light saturation point for photosynthesis should become higher, however it may 


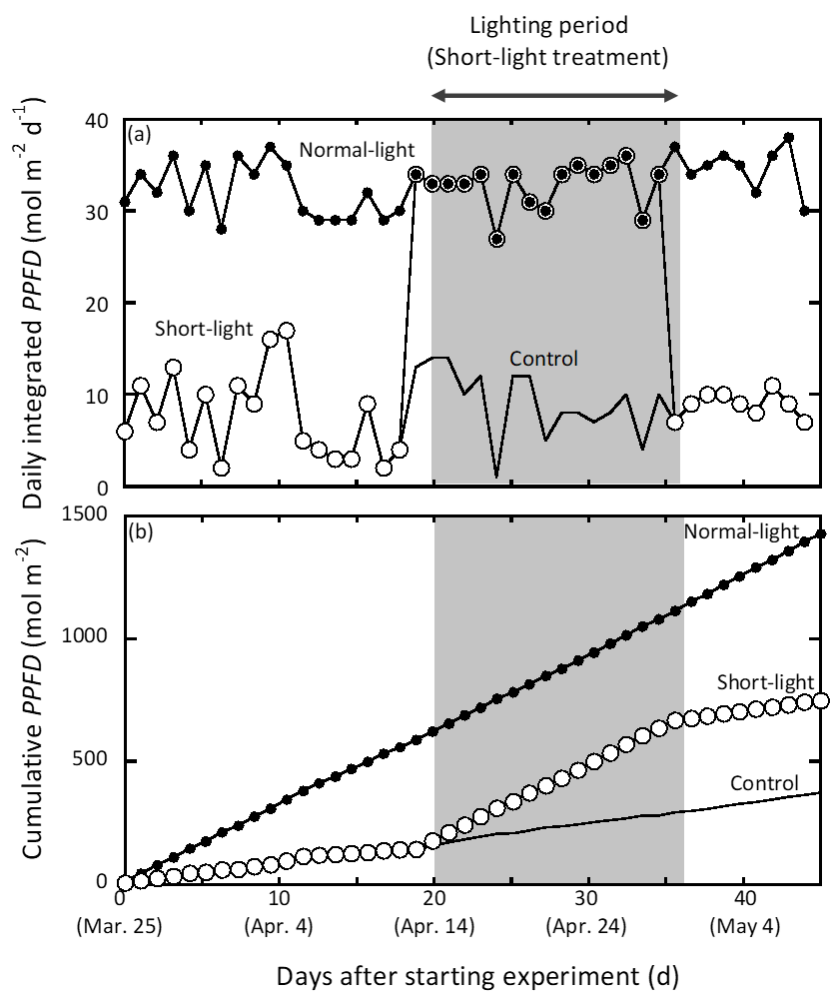

Fig. 1. Diurnal changes in daily integrated photosynthetic photon flux density (PPFD) (a) and cumulative PPFD (b) under the different lighting treatments from March 25 to May 8, 2017: control, natural light; normal-light, supplemental lighting during the entire experimental period (from anthesis to harvest); short-light, supplemental lighting during the active fruit growth period (April 13 to April 28).

not be so large because of the small difference in $\mathrm{CO}_{2}$ concentration $\left(490-400=90 \mu \mathrm{mol} \mathrm{mol}{ }^{-1}\right)$. Thus, a bright environment that exceeds the light saturation point should be created using supplemental lighting. Therefore, supplemental lighting increased the photosynthetic rate by 3 times despite PPFD increasing by 6 times.

The effects of the lighting treatment on the leaf area of strawberry plants is presented in Fig. 3. The leaf areas of all the treatments were nearly identical at the start of the experiment. However, by the end of the experiment, the leaf areas of both the normal-light and the short-light treatments were significantly greater than those of the control treatment. Furthermore, there was no difference between the leaf areas of these lighting treatments. The increase in leaf area was probably promoted by increasing photosynthesis, as shown in Fig. 2, which suggests that even short-term supplemental lighting is sufficiently effective for accelerating the growth of strawberry plants.

The effects of lighting treatment on the DW of strawberry leaves, peduncles, and crowns are presented in Fig. 4. The total DWs of both the normal-light and the short-light treatments were significantly greater than the DW of the control treatment, as was the ratio of leaf to plant body. This result may be attributed to the increased photosynthetic rate

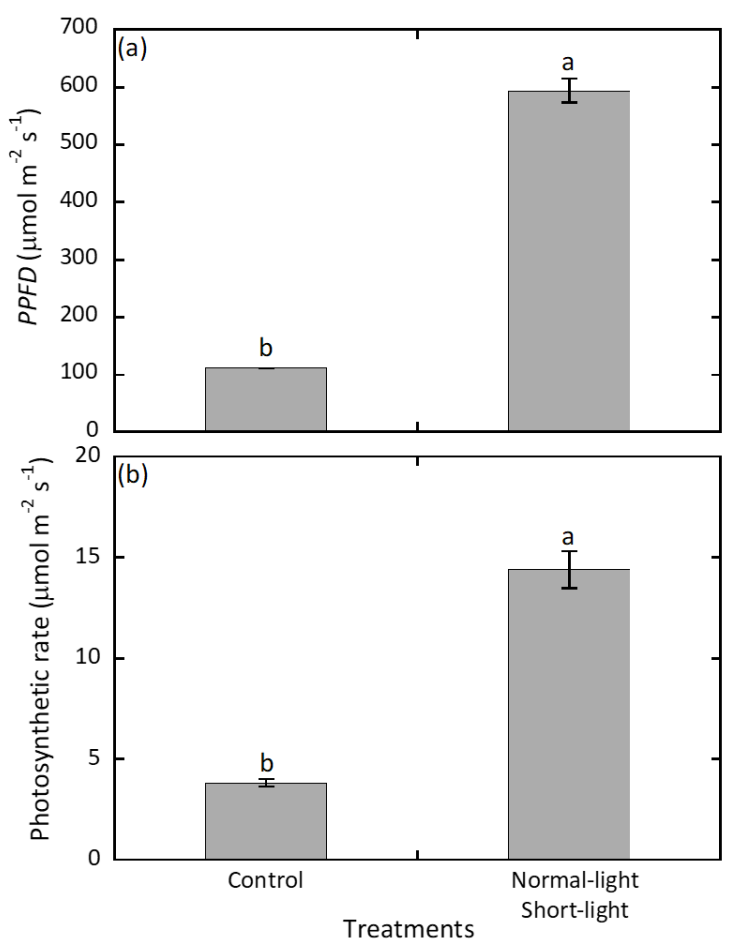

Fig. 2. Photosynthetic photon flux density (PPFD) (a) and photosynthetic rate (b) of fully expanded strawberry leaflets on April 18 (11-12 a.m.) under the different lighting treatments (control, and normal/ short-light). Control, natural light; normal-light, supplemental lighting during the entire experimental period (anthesis to harvest); short-light, supplemental lighting during the active fruit growth period (April 13 to April 28). The photosynthetic rate was measured under the controlled environmental conditions of air temperature at $25^{\circ} \mathrm{C}$, a relative humidity of $50 \%$, and $\mathrm{CO}_{2}$ concentration at $400 \mu \mathrm{mol} \mathrm{mol}^{-1}$ using a leaf chamber. Values are means \pm SE $(n=3)$. Different letters indicate significant differences $(p<0.05)$, according to the t-test.

as shown in Fig. 2. When comparing the normal-light and the short-light treatments, there was no significant difference in total DW. According to Hidaka et al. (2014), the application of supplemental lighting (12 h) increases plant DW. Therefore, these results suggest that short-term supplemental lighting significantly increases plant growth to levels that were almost the same as the increases observed in the normal-light treatment, most likely due to increases in leaf area development, as shown in Fig. 3.

The effects of lighting treatment on the change in fruit volume are presented in Fig. 5. Fruit volume began to increase rapidly at 20 days after anthesis, which is also when the maximum fruit growth rate was observed. The fruit were harvested at either day 30 after anthesis (the normal-light treatment) or day 35 after anthesis (the control and the short-light treatments). Interestingly, the fruit volume harvested from the short-light treatment was almost the same as that harvested from the normal-light treatment, and both supplemental lighting treatments yielded a significantly greater fruit volume than the control treatment. 


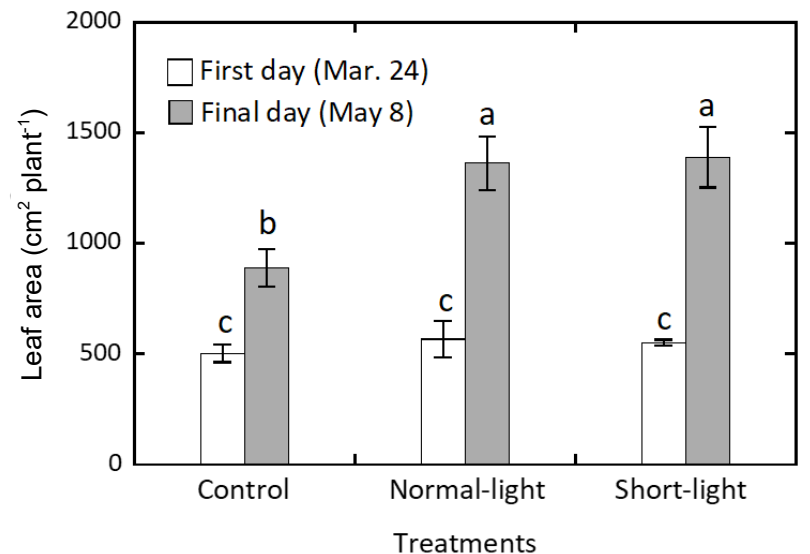

Fig. 3. Leaf area of strawberry plants on the first day (March 24) and last day (May 8) in the experimental period under the different lighting treatments (control, normal-light, and short-light). Control, natural-light; normal-light, supplemental lighting during the entire experimental period (anthesis to harvest); short-light, supplemental lighting during the active fruit growth period (April 13 to April 28). Values are means $\pm \operatorname{SE}(n=6)$. Different letters indicate significant differences $(\mathrm{p}<0.05)$, according to the TukeyKramer test.

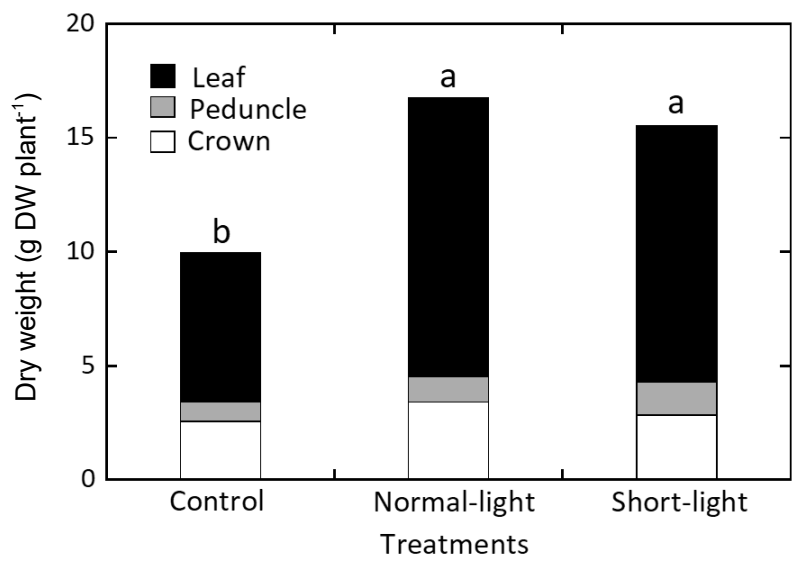

Fig. 4. Dry weights of respective organs of strawberry plants (leaf, peduncle, and crown) final day (May 8) in the experimental period under the different lighting treatments (control, normal-light, and short-light). Control, natural-light; normal-light, supplemental lighting during the entire experimental period (anthesis to harvest); short-light, supplemental lighting during the active fruit growth period (April 13 to April 28). Values are means $(n=6)$. Different letters indicate significant differences $(\mathrm{p}<0.05)$, according to the Tukey-Kramer test.

Therefore, the fruit growth rates of both the normal-light and the short-light treatments were 1.5 times higher than those of the control treatment. Indeed, previous studies have reported that supplemental lighting is effective at increasing both the photosynthetic rate and translocation rate (Miyoshi et al., 2017). Particularly during the period of active fruit growth, the distribution of photosynthetic products to fruit by translocation is at its most active ( $\mathrm{Li}$ et

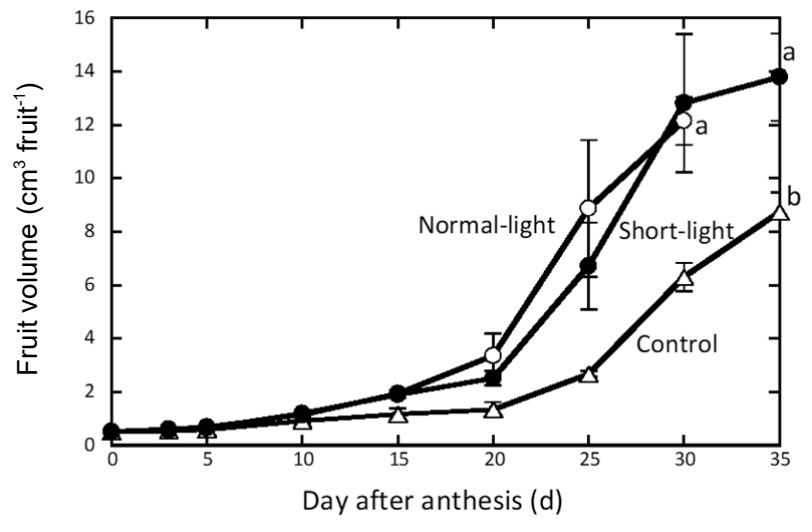

Fig. 5. Time change in fruit volume under the different lighting treatments (control, normal-light, and short-light). Control, naturallight; normal-light, supplemental lighting during the entire experimental period (anthesis to harvest); short-light, supplemental lighting during the active fruit growth period (April 13 to April $28)$. Values are means $\pm \operatorname{SE}(n=3)$. Different letters indicate significant differences $(p<0.05)$, according to the TukeyKramer test.

al., 2013). Therefore, the observed increases in fruit growth rate are most likely the result of increased photosynthetic and translocation rates, which were enhanced by supplemental lighting.

The effects of lighting treatment on the weight of strawberry fruit are presented in Fig. 6 . The FW and DW of the fruit produced by the supplemental lighting treatments were nearly identical, also the FW and DW of the fruit of both the normal-lighting and the short-lighting treatments were significantly greater than those of the control treatment. It may be concluded from these results that supplemental lighting allowed for an increase in fruit size through enhanced photosynthesis (Hidaka et al., 2013). However, there was no significant difference in the dry matter ratio (DW/FW) of the fruit from of all the treatments, probably because supplemental lighting affected FW and DW similarly.

The effects of lighting treatment on the marketable yield of the strawberry plants is presented in Fig. 7. Even though there was no significant difference between the results of the short-light and the control treatments, the average marketable yield of the short-light treatment was higher than that of the control treatment. Similarly, Hidaka et al. (2015) reported that supplemental lighting increased the average marketable yield, but the effect depended to a significant extent on the strawberry variety used.

The effects of lighting treatment on the increase in marketable yield $(\triangle M Y)$, energy use per plant $(E U)$, and energy use efficiency $(E U E)$ are shown in Table 2. Even though there was no significant difference between the results of the short-light and control treatments (Fig. 7), $\triangle M Y$ of the normal-light treatment was 2.4 times higher than that of the short-light treatment. This was consistent with the results of Lu et al. (2011), in which a longer lighting period brought 


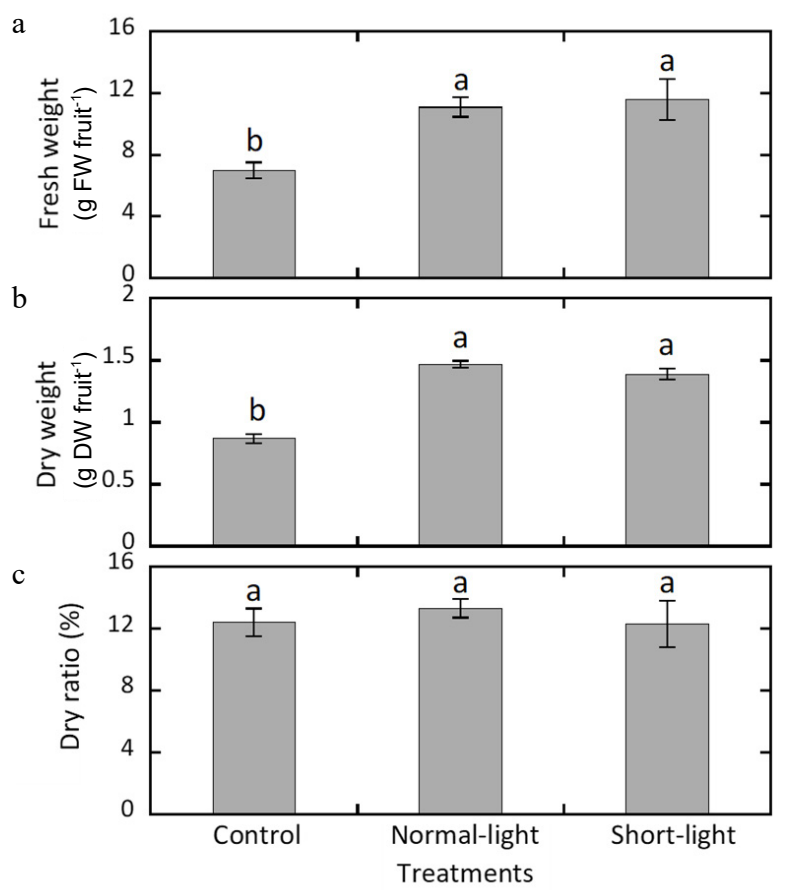

Fig. 6. Fresh weight (FW) (a), dry weight (DW) (b) and dry ratio (DW/FW) (c) of strawberry fruit under different lighting treatments (control, normal-light, and short-light). Control, natural light; normal-light, supplemental lighting during the entire experimental period (anthesis to harvest); short-light, supplemental lighting during the active fruit growth period (April 13 to April $28)$. Values are means $\pm S E(n=3)$. Different letters indicate significant differences $(p<0.05)$, according to the Tukey-Kramer test.

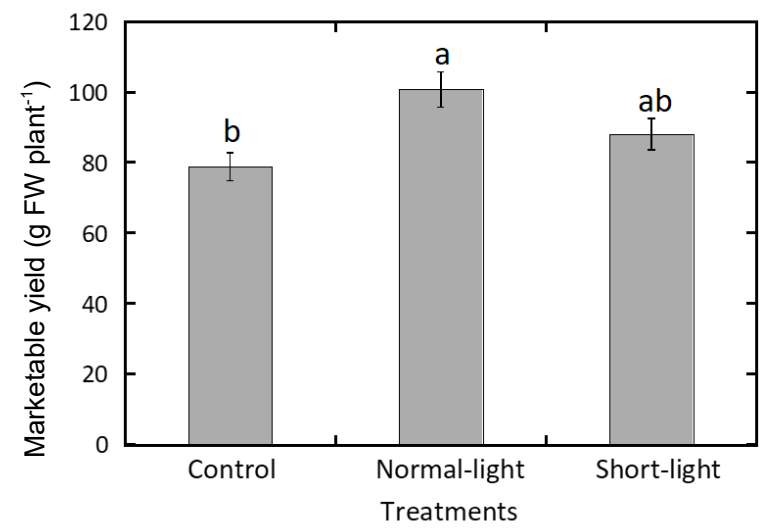

Fig. 7. Yield of strawberry fruit per plant under different lighting treatments (control, normal-light, and short-light). Control, natural-light; normal-light, supplemental lighting during the entire experimental period (anthesis to harvest); short-light, supplemental lighting during the active fruit growth period (April 13 to April 28). Values are means $\pm \operatorname{SE}(n=11,9,11)$. Different letters indicate significant differences $(\mathrm{p}<0.05)$, according to the Tukey-Kramer test.
Table 2. Effect of light treatment on increase of marketable yield $(\triangle M Y)$, energy use per plant $(E U)$, and energy use efficiency $(E U E)$. Control, natural-light; normal-light, supplemental lighting during entire experimental period (anthesis to harvest); shortlight, supplemental lighting during active fruit growth period (April 13 to April 28)

\begin{tabular}{lccc}
\hline Treatments & $\begin{array}{c}\Delta M Y \\
\left(\mathrm{~g} \mathrm{plant}^{-1}\right)\end{array}$ & $\begin{array}{c}E U \\
\left(\mathrm{kWh} \mathrm{plant}^{-1}\right)\end{array}$ & $\begin{array}{c}E U E \\
\left(\mathrm{~g} \mathrm{kWh}^{-1}\right)\end{array}$ \\
\hline Control & 0 & 0 & - \\
Normal-light & 21.9 & 6.74 & 3.25 \\
Short-light & 9.2 & 1.85 & 4.98 \\
\hline
\end{tabular}

about an increased fruit yield in tomato production. On the other hand, $E U$ for the short-light treatment was about one-third of that for the normal-light treatment because the lighting period in the short-light treatment was shorter (15 day) than that in the normal-light treatment (45 day) (Fig. 1). Therefore, the EUE of the short-light treatment was about 1.5 times that of the normal-light treatment.

\section{CONCLUSIONS}

1. This study demonstrated that the application of supplemental lighting during the rapid growth of strawberry fruit promoted plant growth (leaf area, dry weight, fruit volume etc.) through an enhanced photosynthetic rate. As a result, fruit yield also increased.

2. The electricity consumption required for supplemental lighting with LED light sources was considerably reduced by shortening the lighting period (only the rapid fruit development stage was included). As a result, the energy use efficiency of such lighting conditions was increased by 1.5 times as compared with conventional lighting conditions.

3. This experiment was a short-term experiment (MarchMay) that only targeted the third fruit truss. Therefore, in order to demonstrate this energy-saving supplemental lighting technique for practical use, it is necessary to conduct long-term cultivation experiments in the future.

Conflict of interest: The Authors do not declare conflict of interest.

\section{REFERENCES}

Andre G., Hui-lian Xu, and Mohammed D., 1996. Effects of supplemental lighting and fruit thinning on fruit yield and source-sink relations of greenhouse tomato plants. Jpn. Soc. Hortic. Sci., 65(3): 595-601. https://doi.org/10.2503/jjshs.65.595

Araki T., Kitano M., and Eguchi H., 2000. Dynamics of fruit growth and photo-assimilate translocation in tomato plant (Lycopersicon esculentum Mill.) under controlled environment. Acta Hortic., 534:85-92 https://doi.org/10.17660/actahortic.2000.534.8 
Bakker J.C., Adams S.R., Boulard T., and Montero J.I., 2008. Innovative technologies for an efficient use of energy. Acta Hortic., 801(1): 49-62.

https://doi.org/10.17660/actahortic.2008.801.1

Demers D.A., Dorais M., Wien C.H., Gosselin A., 1998. Effect of supplemental light duration on greenhouse tomato (Lycopersicon esculentum Mill.) plants and fruit yields. Sci. Hortic., 74:295-306.

https://doi.org/10.1016/s0304-4238(98)00097-1

Heuvelink E., 2005. Tomatoes: crop production science in horticulture. Oxford, CAB International.

Hidaka K., Dan K., Imamura H., Miyoshi Y., Takayama T., Sameshima K., Kitano M., and Okimura M., 2013. Effect of supplemental lighting from different light sources on growth and yield of strawberry. Environ. Control Biol., 51(1): 41-47. https://doi.org/10.2525/ecb.51.41

Hidaka K., Dan K., Imamura H., Takayama T., Sameshima K., Okimura M., 2015. Variety comparison of effect of supplemental lighting with LED on growth and yield in forcing culture of strawberry. Environ. Control Biol., 53(3): 135-143. https://doi.org/10.2525/ecb.53.135

Hidaka K., Dan K., Miyoshi Y., Imamura H., Takayama T., Kitano M., Sameshima K., and Okimura M., 2016. Twofold increase in strawberry productivity by integration of environmental control and movable beds in a large-scale greenhouse. Environ. Control Biol., 54(2): 79-92.

https://doi.org/10.2525/ecb.54.79

Hidaka K., Okamoto A., Araki T., Miyoshi Y., Dan K., Imamura H., Kitano M., Sameshima K., and Okimura M., 2014. Effect of photoperiod of supplemental lighting with light-emitting diodes on growth and yield of strawberry. Environ. Control Biol., 52(2):63-71. https://doi.org/10.2525/ecb.52.63

Kassai T., Mosoni P., Patyi R., and Dénes F., 2002. Investigation of the dynamics of fruit growth in two strawberry varieties. Acta Hortic., 567:377-379.

https://doi.org/10.17660/actahortic.2002.567.82
Li B., Han Y., and Zhao Y., 2013. Sucrose functions as a signal involved in the regulation of strawberry fruit development and ripening. New Phytol., 198(2): 453-465.

https://doi.org/10.1111/nph.12176

Li Y., Sakiyama R., Maruyama H., and Kawabata S., 2001. Regulation of anthocyanin biosynthesis during fruit development in 'Nyoho' strawberry. J. Jpn. Soc. Hortic. Sci., 70(1): 28-32. https://doi.org/10.2503/jjshs.70.28

Lu N., Maruo T., Johkan M., Hohjo M., Tsukagoshi S., Ito Y., Ichimura T., and Shinohara Y., 2011. Effects of supplemental lighting within the canopy at different developing stages on tomato yield and quality of single-truss tomato plants grown at high density. Environ. Control Biol., 50(1):1-11. https://doi.org/10.2525/ecb.50.1

Martine D., Andre G., and Marc JT., 1990. Annual greenhouse tomato production under a sequential intercropping system using supplemental light. Sci. Hortic., 45: 225-234. https://doi.org/10.1016/0304-4238(91)90067-9

Miura H., Yoshida M., and Yamasaki A., 1994. Effect of temperature on the size of strawberry fruit. Jpn. Soc. Hortic. Sci., 62:769-774.

Miyoshi Y., Hidaka T., Hidaka K., Okayasu T., Yasutake D., and Kitano M., 2017. Dynamics of photosynthate loading in strawberries affected by light condition on source leaves. Environ. Control Biol., 55(1): 53-58. https://doi.org/10.2525/ecb.55.53

Tubiello F.N., Salvatore M., Ross S., Ferrara A., Fitton N., and Smith P., 2013. The FAOSTAT database of greenhouse gas emissions from agriculture. Environ. Res. Lett., 8(1):015009. https://doi.org/10.1088/1748-9326/8/1/015009

Wang SY. and Camp M.J., 2000. Temperatures after bloom affect plant growth and fruit quality of strawberry. Sci Hortic., 85: 183-199. https://doi.org/10.1016/s0304-4238(99)00143-0 